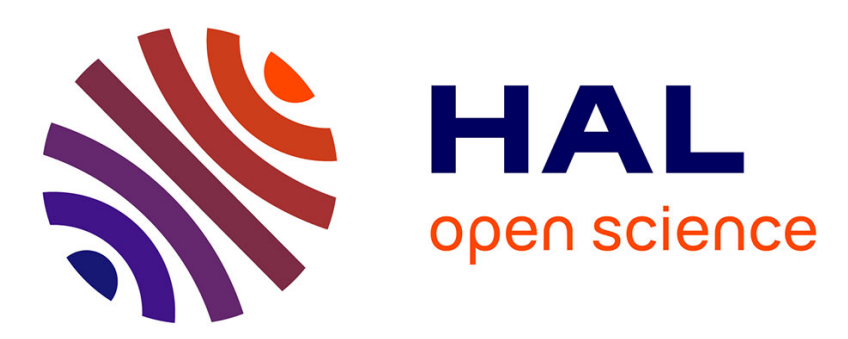

\title{
A multi-level approach to focus, phrasing and intonation in French
}

Mariapaola d'Imperio, James German, Amandine Michelas

\section{To cite this version:}

Mariapaola d'Imperio, James German, Amandine Michelas. A multi-level approach to focus, phrasing and intonation in French. Prosody and Meaning, De Gruyter Mouton, pp.11-34, 2012. hal-00743678

\section{HAL Id: hal-00743678 \\ https://hal.science/hal-00743678}

Submitted on 13 Dec 2012

HAL is a multi-disciplinary open access archive for the deposit and dissemination of scientific research documents, whether they are published or not. The documents may come from teaching and research institutions in France or abroad, or from public or private research centers.
L'archive ouverte pluridisciplinaire HAL, est destinée au dépôt et à la diffusion de documents scientifiques de niveau recherche, publiés ou non, émanant des établissements d'enseignement et de recherche français ou étrangers, des laboratoires publics ou privés. 


\title{
A multi-level approach to focus, phrasing and intonation in French
}

\author{
Mariapaola D'Imperio ${ }^{1}$, James German ${ }^{1,2}$ and Amandine Michelas ${ }^{1}$ \\ ${ }^{1}$ Laboratoire Parole et Langage, CNRS and Aix-Marseille I - Aix-en-Provence, France \\ ${ }^{2}$ Division of Linguistics and Multilingual Studies, Nanyang Technological University \\ mariapaola.dimperio@lpl-aix.fr, jsgerman@ntu.edu.sg,michelas@lpl-aix.fr
}

\begin{abstract}
Much recent work on German and English intonation has addressed the impact of information structure on prosodic patterns in terms of the focus/background partition. In contrast with stress-accent languages such as Italian, Spanish or English, French does not appear to signal focus through pitch accent assignment, rather it appears to mainly exploit prosodic edge marking for the same purposes. The fact that prosodic phrasing is highly sensitive to focus structure is not only true for French, but also for pitch accent languages such as Japanese and Basque (see Gussenhoven 2004 for a discussion), as well as for stress-accent languages (Beckmann \& Pierrehumbert 1986). A previous analysis (Féry 2001) has proposed that French largely exploits phrasing in order to signal focus, and that narrow and contrastive focus "lead to an initial boundary tone, usually high". Here we attempt to build on Féry's insight by showing that, while phrasing is one of the strategies that French adopts in order to signal focus, phrasing cues are different when either the left or the right edge of the focal domain are taken into account. Our findings show that initial LHi rises are associated with the left edge of contrastive focus regions in French, and may therefore serve an important marking function. Crucially, phrase length also contributed to the distribution of LHi, suggesting a probabilistic integration of factors from different levels.
\end{abstract}

\section{Introduction}

Different languages use different methods to signal phrasing, mostly tonal demarcation but also segmental or tonal sandhi rules (cf. Shih 1990 for Chinese), and most of them support the existence of a higher level prosodic unit defined as the Intonation Phrase. This unit is generally understood as corresponding to a sense unit or a syntactic clause, and in traditional phonetic studies it has been linked to the notion of "breath group". Despite the ongoing debate about French intonation structure, most intonation models of French do generally include a high level of constituency, the Intonation Phrase (Post 2000; Jun and Fougeron 2000, 2002), corresponding to the intonation unit of more traditional descriptive work (cf. Di Cristo 2000).

Another basic constituent of the French prosodic hierarchy that is generally agreed upon is a smaller unit, the Accentual Phrase (Jun and Fougeron 1995, 2000, 2002; Welby 2002, 2006), which roughly corresponds to, but does not always overlap with, the Phonological Phrase (see Post 2000; Delais-Roussarie 2005; Astésano et al. 2007). This unit can also be found in non-autosegmental descriptions with different labels, such as the intonème mineur (Delattre 1966; Rossi 1985, 1999), the prosodic word (Vaissière 1992), the rhythmic unit (Di Cristo and Hirst 1993) and the accentual group (Mertens 2004). In most intonation descriptions we also find evidence for the existence of at least one smaller prosodic unit, whose domain might correspond either to a Major or a Minor Phonological Phrase 
(Selkirk 2000), either in the form of an intermediate phrase (Beckman and Pierrehumbert 1986) or of a smaller unit, the Accentual Phrase.

In this paper, we set out to address the complex interaction between initial rise distribution in French and semantic and phrasing factors. Specifically, we argue that the initial rise distribution and its relationship to information structure and syntax is likely to be mediated by an extra level of phrasing, i.e., the intermediate phrase. Through a review of existing proposals and experimental evidence, we further propose that neither a straightforward Focus-to-Accent approach (see Ladd 2008) nor an approach based on phrase edges (e.g. Féry 2001) are able to account for the full range of variability associated with

focus marking in French. We begin, however, with a review of some basic notions of prosodic structure in French.

\subsection{French prosodic structure: Basic notions}

In our approach, we employ the notion of Accentual Phrase (AP) as defined by Jun and Fougeron $(1995,2000)$, whose underlying tonal structure is a LHiLH* sequence (for a detailed description of AP realizations, see Jun and Fougeron 2002). According to this model, the AP is characterized by two tonal events, which in other frameworks may be referred to as primary and secondary accents (Pasdeloup 1990; Di Cristo 2000). The primary accent is a LH* phrase final accent marked by a noticeable $f 0$ movement as well as by preboundary lengthening. Moreover, this tonal sequence is associated with the last full syllable of the AP. The secondary accent is better defined as an initial rise (see AM accounts such as those of Jun and Fougeron 2000; Welby 2002), on the basis of both phonetic and phonological differences between the two tonal rises (see 3.1 below for more detail). 

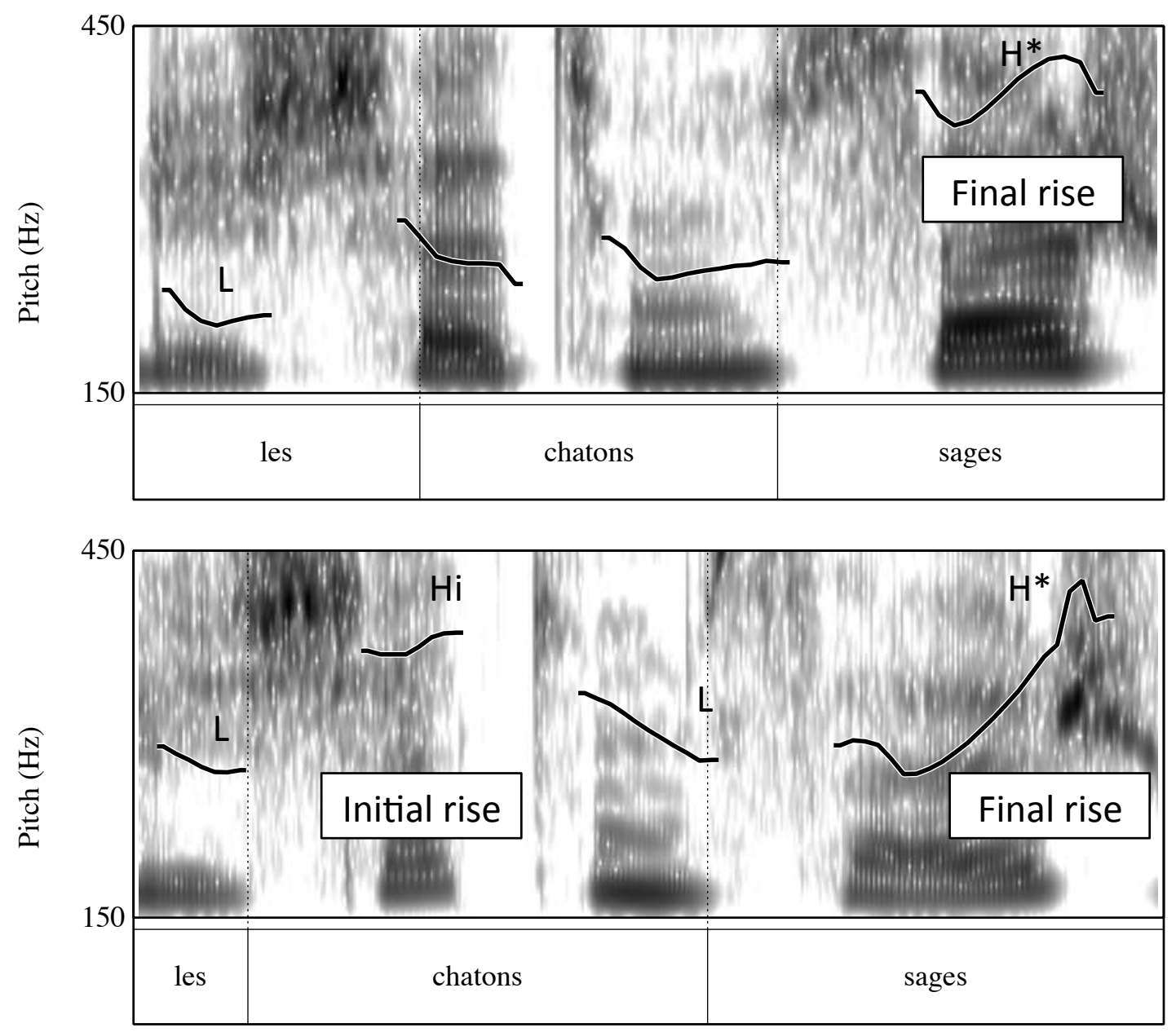

Figure 1: Example of two types of Accentual Phrase for the sequence les chatons sages 'the good kittens' realized with either only a final rise (left) or with an additional/optional early rise (right). (Excerpt taken from the utterance Les chatons sages buvaient leur lait 'The good kittens were drinking their milk' read by a native speaker of French).

Phonologically, only the final accent corresponds to a unique stress location (Dell 1984); phonetically, rhyme lengthening only occurs within the final accent domain, while never within the initial rise domain (Pasdeloup 1990; Astésano, 2001).

Note that both the initial and final (accentual) rises are important markers of phrasal edges, and the location of such edges appears to interact with focus. The fact that prosodic phrasing is highly sensitive to focus structure is not only true for French, but also for pitch accent languages such as Japanese and Basque (see Gussenhoven 2004 for a discussion), as well as for stress-accent languages (Beckmann and Pierrehumbert 1986). However, in contrast with stress-accent languages such as Italian, Spanish or English, French does not appear to signal focus through pitch accent assignment, rather it appears to generally exploit prosodic edge marking for the same purposes. For instance, Féry (2001) has proposed that French largely exploits phrasing in order to signal focus, and that narrow and contrastive focus "lead to an initial boundary tone, usually high". Here we shall attempt to build upon Féry's insight by showing that, while phrasing is one of the strategies that French adopts in order to signal focus, phrasing cues are different when either the left or the right edge of the focal domain are taken into account. Specifically, we propose that in French right edge marking can either reflect the presence of an Accentual Phrase (AP) boundary (whenever a LH* is realized, cf. 
Jun and Fougeron 2000), an Intonation Phrase (IP, signalled through a H\%) or an intermediate phrase (ip) break (Jun and Fougeron 2000; D'Imperio and Michelas 2010), signalled through a $\mathrm{H}$ - tone (cf. Section 2 for a detailed definition).

Very recent work has in fact suggested that the emergence of an ip in French is not simply linked to a specific focus pattern or marked syntactic structure, since a right ip boundary can occur within broad focus utterances whenever the syntactic and prosodic structure allow it (Michelas and D'Imperio 2010a, 2010b, 2010c; D'Imperio and Michelas 2010). While the intermediate phrase break is generally syntax-driven (in that it is found at the NP/VP boundary when the NP is composed of at least 3 APs (cf. D'Imperio and Michelas 2010)), a right-edge intonation phrase break seems to be preferred when the focus domain is very narrow (i.e. restricted to part of a DP, such as an adjective or a demonstrative).

Moreover, the placement of an initial boundary (the initial rise or LHi, cf. Jun and Fougeron 2000; Welby 2002) does not appear to be restricted to the left edge of a Maximal Projection, but can occur towards the left edge of an argument that is part of a complex syntactic constituent, when focus is restricted to a single lexical item. Specifically, recent evidence (German and D'Imperio 2010) suggests that initial LHi rises mark the left edge of contrastive focus regions in French (see LHi on marron in upper panel of Figure 2), but that the probability of LHi also increases with phrase length. In other words, both phrase length and focus scope appear to be the relevant, additive factors for the appearance of an initial rise, and thus it is unlikely that LHi is a focus marker in the traditional sense. The present paper is intended to first touch upon the complexities of the distribution of phonetic and phonological evidence in French that might account for all the variability found in previous and current studies on focus and phrasing.

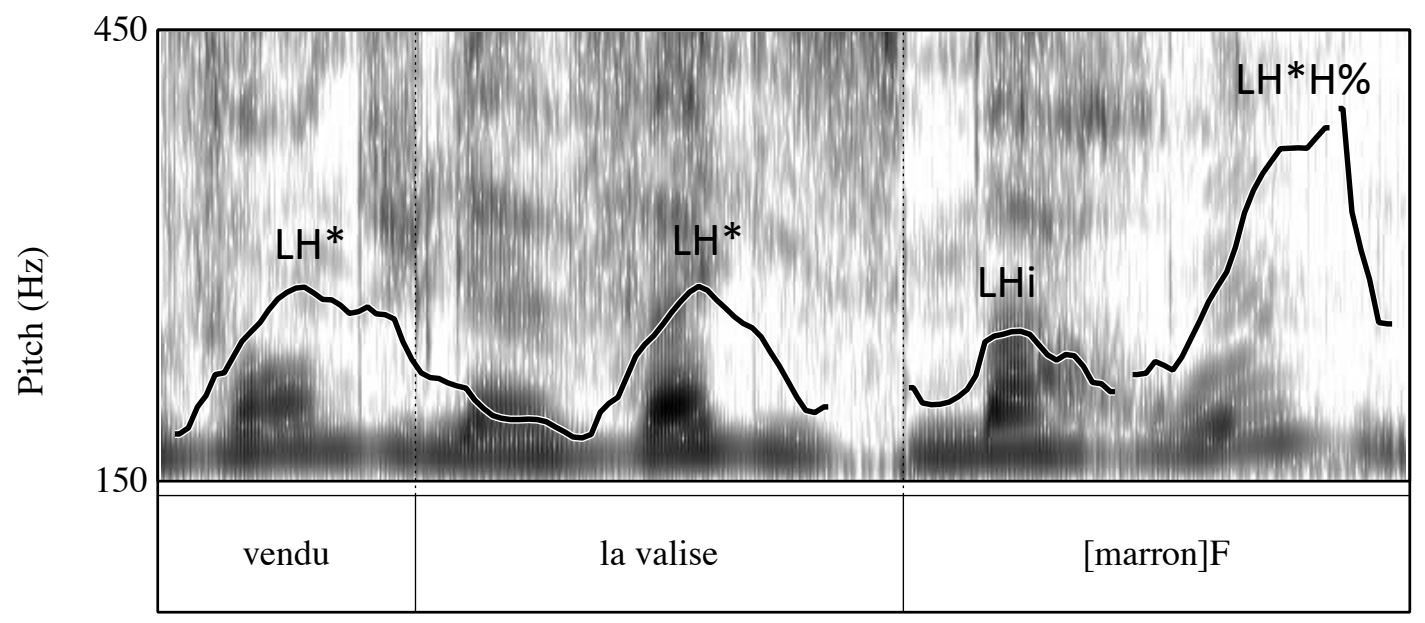

Figure 2 : F0 curve and spectrogram for a section of the sentence Mais à qui est-ce qu'Amélie a vendu la valise marron dans la rue Mignet? 'But to whom has Amelie sold the brown suitcase on Mignet Street?' uttered with narrow focus on marron 'brown'.

\section{The place of the intermediate phrase in the prosodic structure of French}

\subsection{The intermediate phrase in Jun and Fougeron's model}

Two of the most recent autosegmental models of intonation in French, Jun and Fougeron's and Post's models, both agree on the existence of two levels of phrasing in French above the prosodic word: the Intonation phrase (IP) and a lower ranked constituent, which is either 
tonally defined (the Accentual Phrase or AP in Jun and Fougeron's model) or rhythmically defined (the Phonological Phrase in Post's model). In contrast to Post's model, Jun and Fougeron (2000) postulate an additional third level of phrasing ranked between the Intonation Phrase and the Accentual Phrase, i.e. the intermediate phrase (ip), for which we find evidence in a number of stress-accent languages such as English and Italian. The intermediate phrase (ip) is postulated in order to account for specific intonation structures observed in marked syntactic constructions, such as tag-questions, in which a low pitch plateau is usually found after an accentual $\mathrm{H}^{*}$ rise (see Figure 3), as well as for high plateau found after focus in yes/no questions (Jun and Fougeron 2000: 224). According to Jun and Fougeron's first proposal, these low and high plateaus are the result of the presence of either a L- or a Hphrase accent controlling the pitch range from the last pitch accented word up to the final syllable of the phrase (through spreading). In the example in Figure 3, the Intonation Phrase is parsed into two ips. The first ip is right-demarcated by a L- phrase accent controlling the pitch range from the last pitch accent to the end of the intermediate phrase.

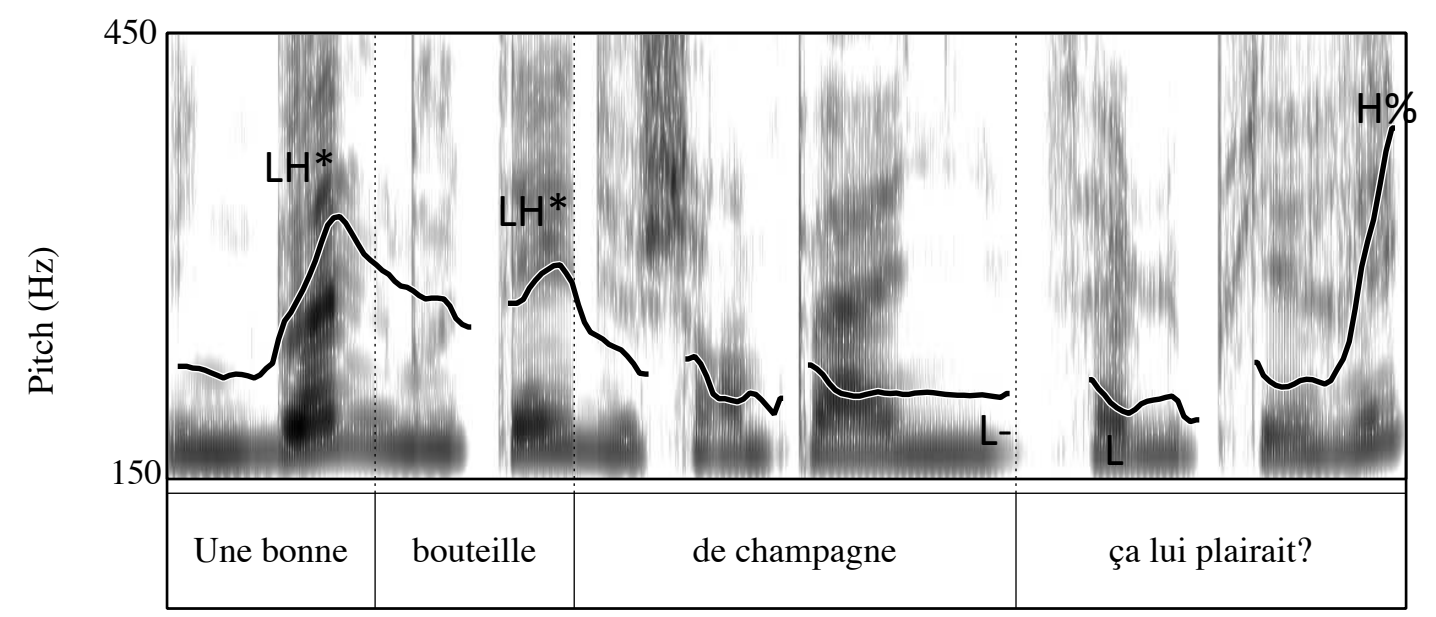

Figure 3: F0 track of the utterance ([Une bonne bouteille de champagne]ip [ça lui plairait)ip)IP 'A good bottle of Champagne, would he like it?' read by native speaker of French.

Hence, Jun and Fougeron introduce the idea of an intermediate level of phrasing in French primarily to account for similar tonal spreading phenomena. In other words, the authors link the emergence of the ip to the presence of specific intonation contours and syntactic structures. However, the authors' later comment suggests that the phonetic and phonological properties of the ip in French are mostly unknown: "It is possible that there is a phonetic difference in the height or shape of $f 0$ rise between $\mathrm{H}^{*}$ and $\mathrm{H}^{*} \mathrm{H}-$, and/or durational cues for this intermediate phrase level" (Jun and Fougeron 2000: 237).

Recent studies (D'Imperio and Michelas 2010; Michelas and D'Imperio 2010a, 2010b, 2010c) offer additional evidence regarding (i) the factors affecting ip distribution and (ii) the phonetic and phonological properties of ip. According to those studies, the intermediate phrase is not restricted to specific intonation contours or syntactic structure but can appear within broad focus (all-focus) utterances if both the syntactic and prosodic structures allow it. We know that prosodic structure is independent of, but related to, both syntactic and information structure. It is also generally assumed that phonological factors such as prosodic weight or speech rate play an important role in prosodic phrasing. Taken together, this evidence suggests that the emergence of an intermediate phrase level in French may be due to two different constraints. First, a syntactic constraint enforces the alignment of the right edge 
of a major syntactic break with the right edge of an ip. Secondly, a size constraint competes with the syntactic constraint by requiring that an ip is made of minimally two APs. In the example sentences in Figure 4, the break between the subject noun phrase (NP) and the verb phrase (VP) is aligned with the ip right boundary, which is itself demarcated by a H- phrase accent.
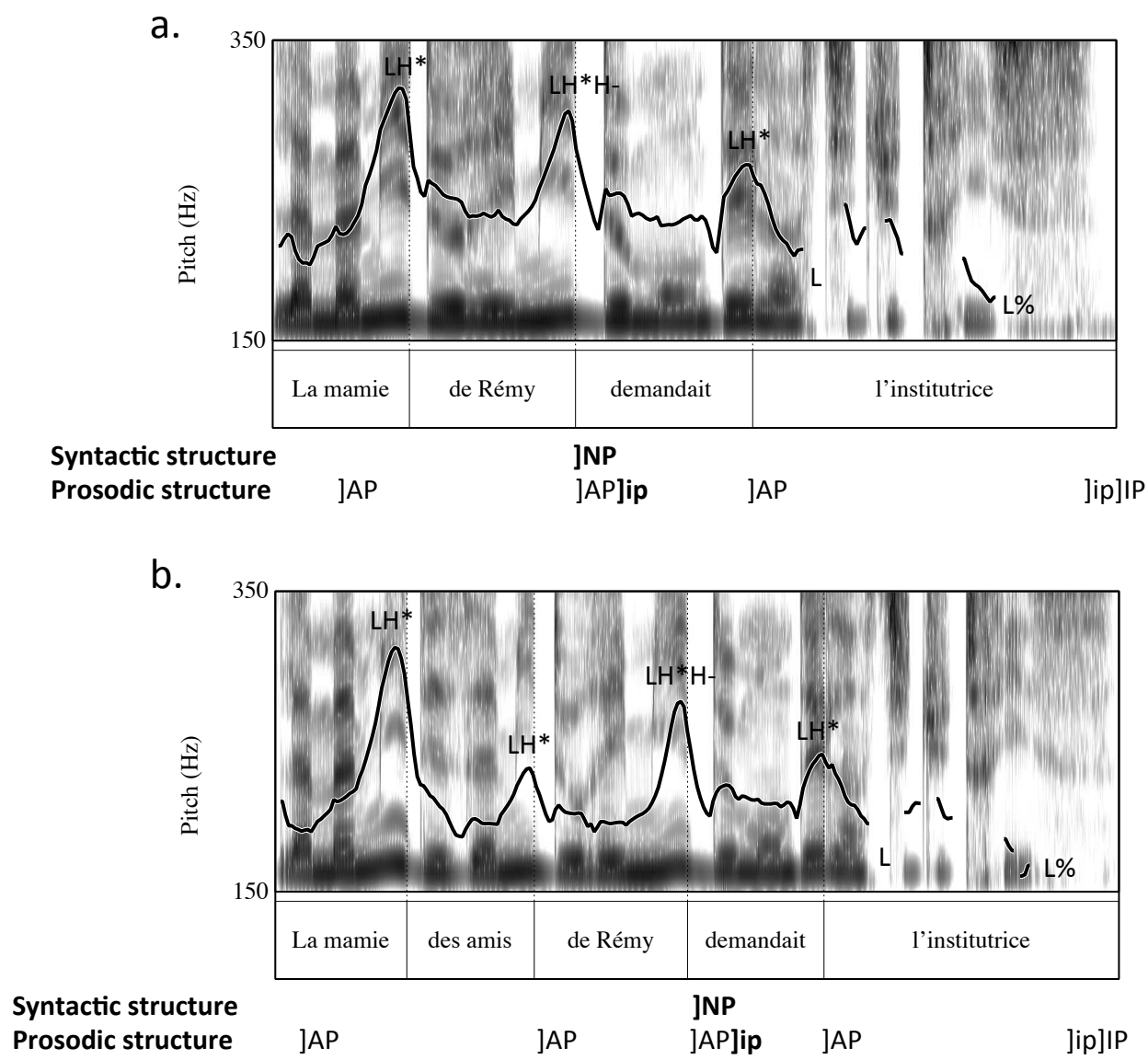

Figure 4: F0 track of the utterance La mamie de Rémy demandait l'institutrice 'Remy's grandmother asked for the teacher' where the subject noun phrase is made of 2 APs (4a) and of the utterance La mamie des amis de Rémy demandait l'institutrice 'The grandmother of Remy's friends asked for the teacher' where the subject noun phrase is made of 3 APs (4b).

Note that the last syllable of the intermediate phrase is produced with final lengthening that is significantly greater than that associated with an AP boundary (Michelas and D'Imperio 2010a). In stress-accent languages such as English or Italian, the ip is also the domain of downstep, and it is delimited at its right edge by a phrase accent. For instance, Beckman and Pierrehumbert (1986) showed that pitch reset is reinitialized after an ip boundary in American English. D'Imperio and Michelas (2010) have recently shown that, as in English, the intermediate phrase of French is the domain of downstep, but what is crucially different is that the pitch is reset right at the intermediate phrase boundary and not after it. Specifically, a Hphrase accent appears to also be responsible for blocking downstep of subsequent LH* within an initial ip (see Figure 4b). 


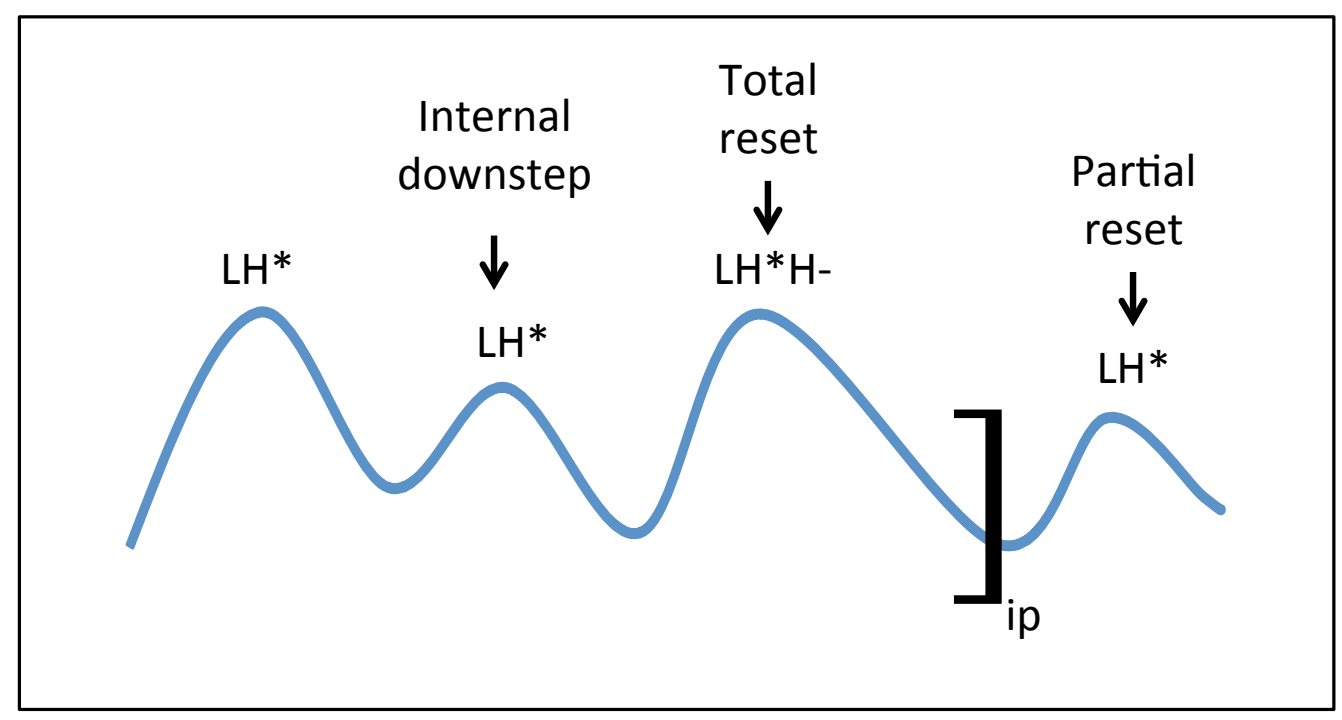

Figure 5: Scheme of ip-internal downstep and both total (at ip edge) and partial (after ip edge) reset for sentences in which the target ip is made of 3 APs.

\section{Information structure and the role of the initial rise}

\subsection{Phonetic and phonological properties of the initial rise}

The initial rise LH rise (LHi) is an optional rise occurring on one of the first syllables of the accentual phrase (Jun and Fougeron 2000). Specifically, Welby (2006) has proposed that the initial rise tends to occur on one of the first syllables of the first content word of the AP, on the basis of evidence of strong alignment between the L target of the rise and the segmental region corresponding to the syllable onset of the content word. It has also been suggested that LHi can be marked by strengthening and lengthening of the syllable onset (Mertens 1992; Astésano 2001; Astésano et al. 2007), though strong empirical evidence is lacking.

Both the final $\mathrm{LH}^{*}$ and LHi appear to be correlated with hyper-articulation (greater tongue displacement, wider lip aperture, increase in duration and peak velocity) of the associated syllable, though a stronger effect is found for LH* (Loevenbruck 1999; Dohen and Loevenbruck 2009). Yet in spite of such accounts, the status of the initial rise is more controversial than that of the final accent, primarily due to the much higher degree of variability associated with its occurrence and realization. Neglected by most studies on French prosody during the first part of the $20^{\text {th }}$ century, more recent models treat the two rises either as the same tonal event or as different events. For instance, in the first autosegmental metrical model of French proposed by Hirst and Di Cristo (1984), the initial and final rise are not distinguished since both correspond to the metrical head of their tonal unit (TU), defined as the minimal unit of synchronisation of tones and segments. Several TUs combine to form a larger unit called intonation unit (IU).

In a more recent and quite different autosegmental-metrical model proposed by Post (2000), both rises are also described as similar, though in terms of two monotonal high pitch accents $\left(\mathrm{H}^{*}\right)$ having the same shape and the same accentual properties (see Figure 6). 


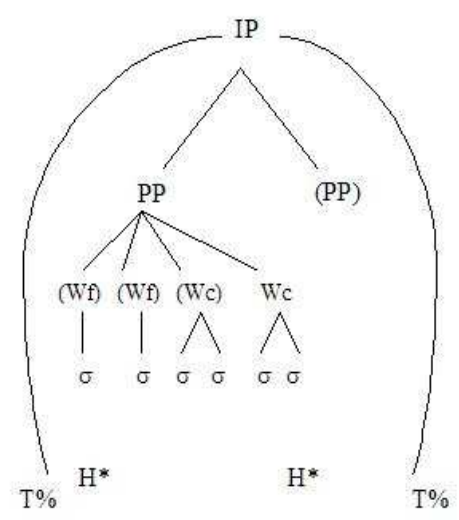

Figure 6: Post's model of French intonation. The intonation phrase IP is demarcated by two boundary tones $\mathrm{T} \%$ and includes one or more phonological phrases PP containing at least one $H^{*}$. Taken from D'Imperio et al. (2007).

In Post's model, the final pitch accent in the intonational phrase can also take the form of a bitonal $\mathrm{H}+\mathrm{H}^{*}$, which is proposed to account for cases in which the $f 0$ peak is aligned with the penultimate syllable of the phonological phrase. Moreover, in that model, the occurrence of a final $\mathrm{LH}^{*}$ is accounted for in terms of phonetic implementation differences by means of a rule leading to the optional insertion of a $\mathrm{L}$ tone between the initial and the final $\mathrm{H}^{*}$ pitch accents ("tone-linking rule", cf. Gussenhoven 2004).

Other authors claim instead that the initial and final rises are structurally different, and that only the final rise is an actual pitch accent. Jun and Fougeron (1995) first proposed that the initial LHi rise is a bitonal phrase accent, associated to the left edge of the AP, while the final accent is a bitonal $\mathrm{LH}^{*}$ pitch accent whose $\mathrm{H}^{*}$ tone is associated to the last full syllable of the accentual phrase (while the L tone is unassociated). In Welby's proposed revision of this model (Welby 2002, 2006, "early L double association hypothesis"), the L tone of the initial rise seeks a primary association with the first syllable of the first content word of the $\mathrm{AP}$ and an optional secondary association with the edge of an earlier syllable, which is often, but not always, the first syllable of the AP. Figure 7 below illustrates Jun and Fougeron's proposal including Welby's revision.

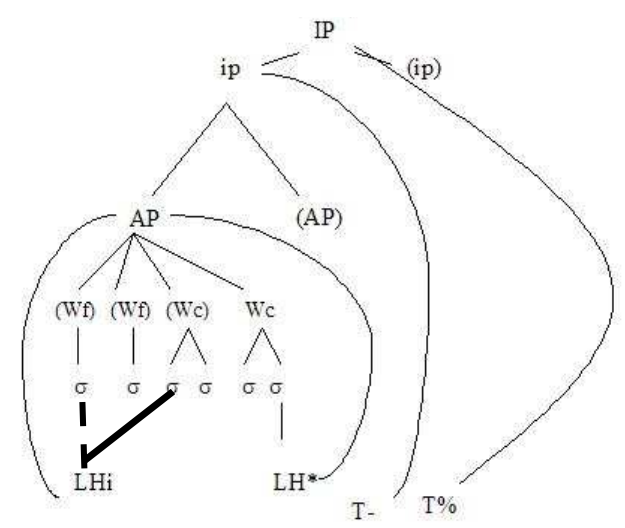

Figure 7: Jun and Fougeron's model with and Welby's (2002, 2006) revision. Primary association of the L tone is shown through a solid line, while the secondary association is shown by the dotted line. 


\subsection{Factors Affecting the Distribution of LHi}

The occurrence of LHi in an accentual phrase is highly variable, and the details of its distribution and realization are poorly understood. While on the one hand LHi is generally considered to be an "optional" feature of AP, its occurrence has been shown to be sensitive to a wide range of factors, including phonological, syntactic, and discourse-level ones. Welby (2006) shows, for example, that the length of an AP is a good predictor of whether LHi occurs in it, such that longer APs are more likely to include LHi than shorter APs. This was true whether length was measured in number of syllables or overall duration, though syllable number was a slightly better predictor for most speakers. The same study showed that LHi occurred more often for slower speaking rates than for faster ones.

Jun and Fougeron (2000) show that position in a sentence matters. In that study, LHi was more likely to occur in APs occurring sentence-initially than for APs in either sentencemedial or sentence-final positions. The authors note additional stylistic and phonological factors that have been suggested by various authors including speaking modality (e.g. imperative vs. exclamation), speaking style (reading vs. spontaneous), segmental composition of the syllable, and syllable structure (open vs. closed, onset vs. no onset) (Fónagy 1980; Vaissière 1974; Lucci 1983).

Syntax can also be relevant for the occurrence of LHi. Astésano et al. (2007) provide the most direct evidence of this, showing that the tendency for LHi (or IA in their presentation) to occur in an AP is correlated with the degree of syntactic embedding of the word boundary occurring at the left edge of that AP. Consider that for the sequence les bagatelles et les balivernes saugrenues ('the crazy trifles and nonsense'), the adjective saugrenues ('crazy') may be interpreted as modifying only the second NP les balivernes ('the nonsense') as in (1b), or as modifying the conjunction of the two NPs les bagatelles et les balivernes ('the trifles and the nonsense') as in (1a). A typical phrasing pattern for this string is shown in (2).

(1) Syntactic possibilities:
a. ([[les bagatelles] et [les balivernes]] saugrenues]) the trifles and the nonsense crazy
'the crazy trifles and nonsense'
b. ([les bagatelles] et [[les balivernes] saugrenues])

(2) Typical phrasing pattern:

(les bagatelles)AP (et les balivernes)AP (saugrenues)AP

This predicts that the embedding level of the syntactic juncture between the two NPs will be lower in (1a) and higher (1b), while the opposite is predicted for the juncture between the second NP and the adjective. The authors show in a controlled production experiment that LHi is more likely to occur when the left edge of $\mathrm{AP}^{1}$ corresponds to a syntactic juncture that is less deeply embedded. In other words, LHi occurred more often at the left edge of the AP comprising saugrenues for (1a) than for (1b), while it occurred more often at the left edge of the AP comprising et les balivernes more often for (1b) than for (1a).

While this finding seems to point to a model in which LHi is recruited to disambiguate syntactic alternatives, it is important to note that phrase length also had an effect on LHi occurrence, such that longer content words were associated with higher rates of LHi. The authors conclude from this finding that LHi is principally a marker of phonological structure, and suggest that the syntactic effects might be indirect and possibly mediated by an intermediate level of phrasing. That both effects were present in the same study suggests a complex picture for the distribution of LHi. 


\subsection{LHi and Information Structure}

The relationship of LHi to information structure presents a similarly complex picture. While focus, contrast and certain types of emphatic meaning are often associated with accentuation of non-final syllables (Di Cristo 1999a, 2000; Jun and Fougeron 2000; Féry 2001, inter alia), typically these involve specialized contours that are distinct from LHi in several ways. Perhaps most significantly, these accents are reported as occurring alone in their phrasal or intonational unit. Additionally, they are typically assumed to be associated to a prominently stressed syllable. LHi, by contrast, always occurs in an AP along with $\mathrm{LH}^{*}$ and has no necessary association to stress. Jun and Fougeron (2000) elicited such specialized non-final accents in contexts like (3b), in which one word was singled out as carrying a corrective meaning.
a. Marion ne mangera pas des ananas au petit déjeuner, mais...
Marion NEG eat.FUT NEG some pineapples at breakfast but
'Marion will not eat pineapples for breakfast, but...'
b. Marion mangera des bananes au petit déjeuner.
Marion eat.FUT some bananas at breakfast
'Marion will eat some bananas for breakfast.'

The authors report that these sentences were generally produced with a single prominent rise (a focus accent, or $\mathrm{Hf}$ ), which was higher than $\mathrm{LH}^{*}$ in a corresponding neutral focus pattern, and was followed by a low plateau extending to the end of the utterance (or a high plateau for polar interrogatives). Although $\mathrm{Hf}$ occurred on both final and non-final syllables, however, the resulting pattern was never LHLH. Such instances of non-final rises therefore more closely resemble the various accents d'insistance or accents emphatiques mentioned by Di Cristo (1999a, 1999b, 2000) and others, and they are distinct from the LHi of the framework we are assuming here.

Di Cristo (2000) observes that non-final rises occur in conjunction with final accents in cases of information focus ${ }^{2}$. In that proposal, constituency at various levels of the grammar may be reflected in prosodic structure by a "bipolarization" effect, whereby "promotion of the extremities" of some constituent results in accents being assigned to both its left and right edges. More recently, Beyssade et al. (2010) present the results of two studies showing that information focus is both marked in production and identified in perception by prosodic highlighting, which in their proposal "involves an initial accentuation, (IA) which may form an accentual arch with the following rising accent, or triggers a high plateau up to the following accent." To the extent that such non-final rises correspond to LHi, this suggests a more complicated picture than even Astésano et al.'s (2007) study presents. It raises the possibility, in other words, that LHi is sensitive not only to phonological, stylistic and syntactic factors, but to discourse-level ones (i.e., focus) as well.

Overall, the relationship between prosody and information structure is not wellunderstood for French. Of the wide range of effects that have been suggested, perhaps the most well-documented is that the region between the end of a corrective or emphatic focus and the end of the sentence (or post-focal region) may exhibit a marked reduction in $f 0$ range and $f 0$ movement. In declaratives, this takes the form of a low plateau extending from the end of the last major falling event, while for polar interrogatives this is a high plateau extending more or less from the highest point of the last rise (Jun and Fougeron 2000). The phenomenon has variously been formulated in terms of dephrasing or deaccenting, though Jun and Fougeron (2000) show that such regions maintain their durational cues to phrasing, and thus may not be appropriately characterized as "dephrased".

On the view that the location and extent of the focused constituent form part of a speaker's intentions that must be recovered by the listener, then post-focal deaccenting 
provides an effective cue to the location of the right edge of focus, since it marks a kind of transition point between the focal region and the post-focal region. It is not clear whether such cues exist for signaling the left edge of focus in French. For one thing, there does not seem to be the equivalent of prefocal deaccenting. Instead, both the prefocal and focal regions are, subject to conditions of rhythm and syntax, phrased into APs bearing final rises. The result is a more or less continuous distribution of accentual features that span the boundary between the prefocal and focal regions. Consider the sentence from (3b) shown in (4) with hypothetical foci of two different sizes having different left edges.

\begin{tabular}{|c|c|c|}
\hline Marion & mangera & [des bananes]F au petit déjeuner \\
\hline$)_{\mathrm{AP}}$ & )$_{\mathrm{AP}}$ & )$_{\mathrm{AP}}$ \\
\hline $\mathrm{LH}^{*}$ & $\mathrm{LH}^{*}$ & $\mathrm{LH}^{*}$ \\
\hline Iarion & [mangera & des bananes]F au petit déjeuner \\
\hline $\begin{array}{r})_{\mathrm{AP}} \\
\mathrm{LH}^{*}\end{array}$ & $\begin{array}{c})_{\mathrm{AP}} \\
\mathrm{LH}^{*}\end{array}$ & $\begin{array}{c})_{\mathrm{AP}} \\
\mathrm{LH}^{*}\end{array}$ \\
\hline
\end{tabular}

Notice that in both cases, regular phrasing into APs results in an identical distribution of $\mathrm{LH}^{*}$ accents. Thus, if only the distribution of $\mathrm{LH}^{*}$ is considered, it is not possible for a listener to recover the location of the left edge of focus in such a case. While there is limited evidence that the pre-focal region is distinguished from the focal region by having a compressed $f 0$ range (Touati 1987; Jun and Fougeron 2000; Dohen and Loevenbruck 2004), it has not yet been established whether this is a reliable marker that could be used by the listener to recover the position of the left edge of focus.

In both Jun and Fougeron (2000) and other quantitative studies (Dohen and Loevenbruck 2004), focus is conceptualized in terms of corrective or emphatic contrast. Féry (2001) reports on a production study involving a notion of focus based on direct answers to wh-questions, though the quantitative results are not presented. Other work has emphasized the role of additional focus-like categories including intensification (Di Cristo 2000) and information focus (Di Cristo 2000; Beyssade et al. 2010). Krifka tentatively proposes to unite the various notions of focus cross-linguistically under the idea that it is used to "indicate the presence of alternatives that are relevant for the interpretation of linguistic expressions" (Kifka 2007: 18). What it means to be "relevant for interpretation" may vary depending on the particular phenomenon being observed. In the case of certain focusing adverbs, for example, the way in which focus gives rise to alternatives may have consequences for the truth conditions of the sentence. In its more pragmatic uses, focus may be relevant for interpretation because it establishes parallels between different linguistic units in the same discourse. This latter notion is closely related to Rooth's (1992) construal of Contrastive Focus and forms the basis of a pair of studies conducted by German and D'Imperio (2009, 2010).

In the first of these studies, German and D'Imperio (2009) found preliminary evidence that initial rises are more likely to occur in APs whose left edge coincides with the left edge of a contrastive focus. In that study, a reading task was used to elicit contrastive focus in polar interrogative clauses that were preceded by closely parallel clauses. This is illustrated in (5).

(5) a. Je sais qu'Amélie a vendu la valise jaune dans la rue Mignet, mais... I know that Amélie has sold the suitcase yellow in the street Mignet but "I know that Amélie sold the yellow suitcase on Mignet Street, but..." b. ... a qui est-ce qu'Amélie a vendu la valise [marron]F dans la rue Mignet? to whom is it that Amélie has sold the suitcase brown in the street Mignet

"...to whom did Amélie sell the [brown]F suitcase on Mignet Street?"

Since the two complement clauses in (5a) and (5b) differ only in the value of the adjective modifying the noun valise, the prediction is that marron ('brown') is established in this context as a contrastive focus. Keeping the target sentence (5b) fixed, the context was 
then varied in a way that systematically established foci of different sizes. In (6) and (7), for example, the complement clause in the first sentence in each pair differs from that in the second sentence in such a way as to establish the direct object (la valise marron) and the VP (vendu la valise marron) as the contrastive foci in (6b) and (7b), respectively. Note that the location of the right edge of the contrastive focus region is not predicted to differ across the two contexts.

a. Je sais qu'Amélie a vendu la caméra dans la rue Mignet, mais...

I know that Amélie has sold the camera in the street Mignet but

"I know that Amélie sold the camera on Mignet Street, but..."

b. ... a qui est-ce qu'Amélie a vendu [la valise marron]F dans la rue Mignet?

to whom is it that Amélie has sold the suitcase brown in the street Mignet

"...to whom did Amélie sell [the brown suitcase]F on Mignet Street?"

a. Je sais qu'Amélie a déjeuner dans la rue Mignet, mais...

I know that Amélie has eaten lunch in the street Mignet but

"I know that Amélie ate lunch on Mignet Street, but..."

b. ... a qui est-ce qu'Amélie a [vendu la valise marron]F dans la rue Mignet?

to whom is-it that Amélie has sold the suitcase brown in the street Mignet

"...to whom did Amélie [sell the brown suitcase] on Mignet Street?"

In short, LHi showed a tendency to "track" the left edge of focus across three different contexts by occurring on the AP whose left edge coincided with the left edge of the focus (see Figure 2). While the overall number of items in the study was low, the observation echoes Di Cristo's (2000) suggestion that initial rises (or LHi) may be one structural feature that can be recruited to mark the location of the left edge of focus.

In a follow-up study, German and D'Imperio (2010) more directly addressed the question of whether LHi marks the left edge of focus. The targets in that case were whquestions including a direct object consisting of a 3-syllable noun phrase (i.e., le merlan) and either a 3- or 5-syllable prepositional phrase (underlined), followed by a temporal modifier. This is illustrated in (8).

a. 3-syllable (short): Qui a commandé le merlan aux navets ce soir? who has ordered the whiting with turnips this evening "Who ordered the whiting with turnips this evening?"

b. 5-syllable (long): Qui a commandé le merlan aux macadamias ce soir? who has ordered the whiting with macadamias this evening "Who ordered the whiting with macadamias this evening?"

These sentences were elicited as the second of a series of three information-seeking questions $^{3}$. Thus, specific patterns of focus were induced by manipulating the size of correspondence between the target and the questions occurring before and after it. In (9b), for example, the focused element is predicted to be the entire direct object [le merlan aux navets], since the surrounding context (i.e., (9a) and (9c)) suggests that that constituent is the relevant point of contrast. In the PP-focus condition shown in (10b) on the other hand, the focus is limited to the prepositional phrase aux navets for similar reasons. Thus, each target item occurred in each of four conditions: DO-Focus/short, DO-Focus/long, PP-Focus/short and PPFocus/long.

(9) DO-Focus

a. Qui a commandé l'entrecôte ce soir?

who has ordered the steak this evening

"Who ordered the steak this evening?"

b. Qui a commandé [le merlan aux navets]F ce soir?

who has ordered the whiting with turnips this evening

"Who ordered the whiting with turnips this evening?" 
c. Qui a commandé les gambas ce soir?

who has ordered the prawns this evening

"Who ordered the prawns this evening?"

(10) PP-Focus

a. Qui a commandé le merlan à la sauce citron ce soir?

who has ordered the whiting with the sauce lemon this evening

"Who ordered the whiting with lemon sauce this evening?"

b. Qui a commandé le merlan [aux navets]F ce soir?

who has ordered the whiting with turnips this evening

"Who ordered the whiting with turnips this evening?"

c. Qui a commandé le merlan aux câpres ce soir?

who has ordered the whiting with capers this evening

"Who ordered the whiting with capers this evening?"

If LHi marks the left edge of focus, then the prediction is that LHi should be more likely to occur at the left edge of an AP comprising the noun phrase in the case of (9b) (since that is also predicted to be the left edge of the contrastive focus), while it should be more likely to occur on an AP comprising the prepositional phrase in a case like (10b). Recall, however, Welby's (2006) finding that longer APs are more likely to include LHi. On the assumption that the prepositional phrase comprises a single AP in both (8a) and (8b), this leads to a second, independent prediction that LHi should be more likely to occur on the prepositional phrase when it is long than when it is short.

In fact, the results of 192 tokens taken from eight speakers showed a fairly strong correlation between focus and LHi. For the position corresponding to the left edge of the prepositional phrase, LHi was more likely when that position coincided with the focus left edge $(51 \%$ versus $33 \%)$, as illustrated in Figure 8 . Similarly for the left edge of the noun phrase, LHi was significantly more likely when that position coincided with a focus edge (34\% versus $21 \%$ ). Importantly, the length of the prepositional phrase also mattered. As predicted, LHi was more likely to occur on the prepositional phrase when it was long $(54 \%)$ than when it was short (30\%).

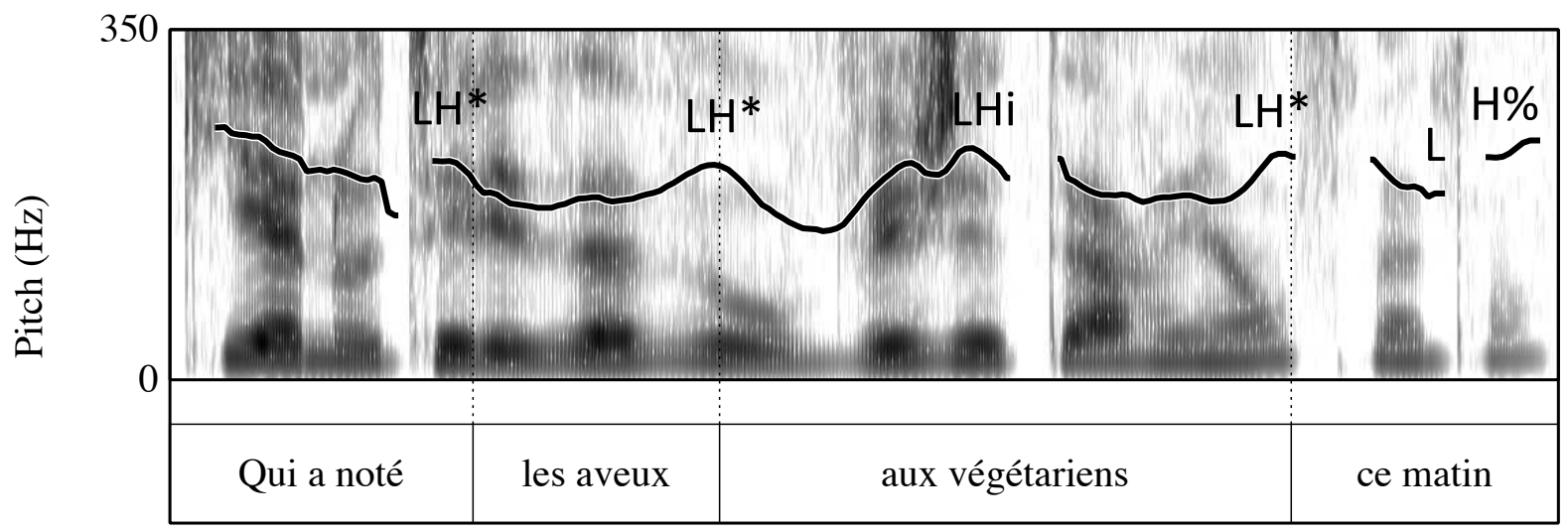

Figure 8: LHi realized at the left edge of the prepositional phrase in a PP-focus context (long) for one speaker in the utterance Qui a noté les aveux [aux végétariens] $F$ ce matin 'Who wrote down the confessions to the vegetarians this morning'.

Statistical analysis ${ }^{4}$ revealed that both factors (length and focus size) were significant for the occurrence of LHi for the position corresponding to the left edge of the prepositional phrase. However, the analysis revealed no interaction between these factors. In other words, the effect of focus size was constant whether the prepositional phrase was long or short. Conversely, 
prepositional phrase length had a constant effect whether the focus included just the prepositional phrase or the entire direct object.

This latter finding is somewhat surprising. Consider that if the realization of LHi is directly related to AP length, due, for example, to some (possibly probabilistic) constraint on the minimum size of AP that will support both LHi and $\mathrm{LH}^{* 5}$, then LHi should be so unlikely in very short APs that its occurrence is insensitive to the locations of focus boundaries. In the limit, one-syllable APs cannot support LHi at all ${ }^{6}$. Similarly, if the relationship between LHi and phrase length is due to a rhythmic constraint requiring longer APs to include LHi, then LHi should be so common in very long APs (e.g., seven syllables) that the effects of focus are negligible. Instead, the data show that the effects of both factors are independent and additive, at least for the particular range of AP length that was addressed.

Consider also the implications of the fact that LHi was sensitive to both AP length and focus. It suggests, among other things, that LHi is not a marker of focus in the traditional sense. Given that LHi is sensitive to AP length at all, in other words, the association between LHi and focus can only ever be partial or imperfect at best. Setting aside for a moment the issue of precision in the study, a follow-up analysis showed that a listener who uses LHi as the sole indicator of focus size would be able to make the correct prediction only $60 \%$ of the time ${ }^{7}$. A similar remark applies to the findings of Astésano et al.'s (2007) study.

\section{Discussion}

The findings presented above suggest that the relationship between LHi and each of the factors influencing its distribution is indirect in one or more ways. But what type of model could capture such effects without assuming a direct relationship? Astésano et al. (2007) conclude from their results that LHi is first and foremost a reflex of phonological structure, and on that basis suggest that it is linked to an intermediate level of phrasing. While the authors do not propose a specific mechanism along these lines, there are certain characteristics that such a model would have to include in order to account for the observed correlations. In what follows, we outline some of those characteristics and suggest promising approaches for incorporating them into existing models. However, in the absence of further data, for example, linking the effects of syntax with the effects of focus and phrase length, or a more direct metric for the identification of ip, we stop short of making an explicit proposal.

One promising approach to indirect relationships like those suggested by the data above is to assume that an additional level of description, such as ip, mediates between the two levels of primary interest. To explain the association between focus and LHi, for example, we might assume that the operative principle involves a rule or constraint requiring that a focus constituent project this intermediate level. In short, a focus constituent must be contained in a single ip ${ }^{8}$. A very similar proposal would apply to the syntactic effects: all else being equal, a less embedded syntactic constituent has a greater tendency to project an iP than a more embedded one.

Such a principle might itself be weak, probabilistic, or even optional. We know from the D'Imperio and Michelas (2010) studies, for example, that ip boundaries appear at the subject-VP juncture in broad focus utterances, so any focus-based rule or constraint must at a minimum accommodate the role of syntax. Pierrehumbert (1994) proposes that for English, there is a variable constraint on the size of the prosodic domain that gets promoted to a level of stress that would be sufficient for accentuation. This process of prosodic promotion is not random in that account, but may "reflect discourse factors" (Pierrehumbert 1994: 15) and is "generally available to strengthen prosodically weak elements if the speaker for any reason wishes to accent them" (Pierrehumbert 1994: 13). In the case of French, the process would 
apply to promote a given constituent, not to a higher degree of stress, but to a higher level unit in the prosodic hierarchy. Thus, a string that is initially parsed as an AP within some larger ip, would by way of prosodic promotion be reparsed as its own ip. In effect, the suggestion is that speakers select, with some variability, the size of the unit to which this process applies based on discourse needs such as signalling the scope of focus or disambiguating between possible syntactic parses.

Note that it is not sufficient to establish a relationship between focus or syntax and ip. The link still needs to be made between LHi and ip. Importantly, however, the results of the Michelas and D'Imperio (2010b) studies are not suggestive of a one-to-one association between these two levels either (though no conclusive analysis has been conducted). More data is needed to determine whether this relationship is itself probabilistic, or whether there are additional factors or levels of description that are still unaccounted for.

Finally, any viable model needs to account for the effects of length on LHi. One fairly straightforward approach is to assume that longer APs are more likely to be parsed as their own ip. Similar to the case of focus, this in turn could be explained by a probabilistic or stylistically driven constraint on the domain of ip assignment. Thus, with the single assumption that LHi is a feature of an ip (as opposed to an AP), it is possible to explain why longer APs are more likely to include LHi without invoking either rhythmic or tonal crowding constraints, which are not suggested by the data in any case.

The model elements sketched above are merely suggestive, and we wish to be clear that there is currently is no data that straightforwardly supports one particular model over any other. However, the fact that the data may be explained by assuming a level of prosodic structure for which there is independent evidence is, we believe, significant. The purpose of presenting it in this fashion is therefore to highlight the potential for complex interactions in a problem that is typically approached from only one perspective. On the one hand, a traditional focus-to-accent approach seeks to identify robust markers of information structure in the traditional sense, leaving little role for structural effects at the level of phrasing, for example. Crucially, it cannot explain why the left edge of a focus region would be so unreliably marked given that it is marked at all, or why LHi is sensitive to so many different factors. On the other hand, a phrasing or edge-based approach that emphasizes the comparative lack of intonational "marking" in French as compared with Germanic languages, for example, has too little to say about the role of post-focal deaccenting on the one hand, and the complex distribution of LHi on the other. The point we wish to highlight here is that the type of data that will eventually lead to an adequate model of prosody and information structure in French will need to take into account both issues simultaneously by, for example, establishing the relative effect size of factors from different levels of description within the same study, following the precedent of Astésano et al. (2007), German and D'Imperio (2010), and others. Moving forward, then, our approach seeks an integrated model that takes into account both types of descriptions, as well as any additional interdepencies that they bring to the problem.

\section{Acknowledgments}

We would like to thank two anonymous reviewers and the editors of this volume for helpful comments on this paper. This research was partly funded by a grant from the ANR (Agence Nationale de la Recherche), Pro-Gram "La Prosodie dans la Grammaire", from the French Ministry of Research.

\section{Notes}


1 Note that AP is reserved solely for reference to the Accentual Phrase throughout our discussion, and not to the Adjective Phrase.

2 In direct answers to wh-questions, an information focus is the portion of the utterance that corresponds to the wh-element of the question that it resolves.

3 The participants used the questions to retrieve specific pieces of information from a speaking partner in a cooperative task.

4 The data were modeled using mixed effects linear regression treating PP-length and focus size as fixed effects, and items as random effects.

5 In Post's (2000) proposal, non-final accents essentially represent a strategy for stress-clash avoidance after restructuring (i.e., boundary erasure). Since restructuring typically leads to larger phrases, non-final accents are predicted to be unnecessary in very small phrases.

6 In Jun and Fougeron's (2000) proposal, each tone must be realized on its own syllable, and every AP must include at least one low tone. This predicts that LHi should be impossible for even a two-syllable AP, though Welby (2006) shows experimentally that this prediction is not born out. In that study, initial rise occurred on $13 \%$ of all two-syllable words.

7 A chi-square showed that this rate differed from chance $(51 \%)$ at the $\mathrm{p}<0.1$ level.

8 Notice the similarity to Féry's (2001) proposal, which suggested that a focus is constraint to project its own phonological phrase.

\section{References}

Astésano, Corinne 2001 Rythme et accentuation en français : Invariance et variabilité stylistique. Paris: L'Harmattan.

Astésano, Corinne, Ellen Gurman Bard and Alice Turk 2007 Structural influences on initial accent placement in French. Language and Speech 50(3): 423-446.

Beckman, Mary and Janet Pierrehumbert 1986 Intonational Structure in Japanese and English. Phonology Yearbook III, 15-70.

Beyssade, Claire, Barbara Hemforth, Jean-Marie Marandin and Crisetl Portes 2010

Information focus in French. Proceedings of Speech Prosody 2010, 100109:1-4. Chicago, United States.

Delattre, Pierre 1966 Les dix intonations du français. The French Review 40(1): 1-14.

Dell, François (1984) L'accentuation dans les phrases en français. In : François Dell, Daniel Hirst and Jean-Roger Vergnaud (eds.), Forme Sonore du Langage: Structure des Représentations en Phonologie, 65-122. Paris: Hermann.

Di Cristo, Albert and Daniel Hirst 1993 Rythme syllabique, rythme mélodique et représentation hiérarchique de la prosodie du français. Travaux de l'Institut de Phonétique d'Aix-en-Provence, 9-24.

Di Cristo, Albert 1999a Vers une modélisation de l'accentuation en français. Première partie: la problématique. Journal of French Language Studies 9: 143-179. 
Di Cristo, Albert 1999b Le cadre accentual du français contemporain: Essai de modélisation. Première partie. Langues 2 (3): 184-205 and Langues 2 (4): 258-267.

Di Cristo, Albert

2000 Vers une modélisation de l'accentuation en français. Deuxième partie: Le modèle. Journal of French Language Studies 10 :27-44.

Delais-Roussarie, Elizabeth

2005 Interface Phonologie / Syntaxe : des domaines phonologiques à l'organisation de la Grammaire. In : Jacques Durand, Noël Nguyen, Véronique Rey and Sophie Wauquier-Gravelines (eds.), Phonologie et Phonétique: Approches actuelles, 159-184. Paris: Hermès.

D’Imperio, Mariapaola, Roxane Bertrand, Albert Di Cristo and Cristel Portes 2007 Investigating phrasing levels in French: Is there a difference between nuclear and prenuclear accents?. In: José Camacho, Viviane Déprez, Nydia Flores and Lilian Sanchez (eds.), Selected Papers from the 36th Linguistic Symposium on Romance Languages (LSRL), 97-110. New Brunswick: John Benjamins Publishing Company.

D'Imperio, Mariapaola and Amandine Michelas 2010 Embedded register levels and prosodic phrasing in French. Proceedings of the Speech Prosody 2010 Conference, 100879:14. Chicago, United-States.

Dohen, Marion and Hélène Loevenbruck 2004 Pre-focal rephrasing, focal enhancement and post-focal deaccentuation in French. Proceedings of the 8th International Conference on Spoken Language Processing, 785-788. Jeju, Korea.

Dohen, Marion and Hélène Lœvenbruck 2009 Interaction of audition and vision for the perception of prosodic contrastive focus. Language \& Speech 52(2-3): 177-206.

Feldhausen, Ingo 2008 The Prosody-Syntax Interface in Catalan. $\mathrm{PhD}$ thesis. University of Postdam, Germany.

Féry, Caroline 2001 Intonation of focus in French. In: Caroline Féry and Wolfgang Sternefeld (eds.), Audiatur Vox Sapientes: A Festschrift for Arnim von Stechow, 153-181. Berlin: Akademi Verlag.

German, James and Mariapaola D'Imperio 2009 Information structure and the alignment of phrasal features in French qu-interrogatives. Poster presented at the international conference Interfaces Discours et Prosodie, Paris, France.

German, James and Mariapaola D'Imperio 2010 Focus, phrase length, and the distribution of phrase-initial rises in French. Proceedings of International Conference on Speech Prosody 2010, 100207:1-4. Chicago, United-States.

Gussenhoven, Carlos 2004 The Phonology of Tone and Intonation. Cambridge: Cambridge University.

Hirst, Daniel and Albert Di Cristo 1984 French intonation: a prametric approach. Die NEuren Sprache 83(5): 554-569. 
Jun Sun-Ah and Cécile Fougeron 1995 The Accentual Phrase and the Prosodic Structure of French. Proceedings of the 13th International Congress of Phonetic Sciences 2: 722-725. Stockholm, Sweden.

Jun Sun-Ah and Cécile Fougeron 2000 A Phonological model of French intonation. In: Antonis Botinis (eds.), Intonation: Analysis, Modeling and Technology, 209-242. Dordrecht : Kluwer Academic Publishers.

Jun Sun-Ah and Cécile Fougeron 2002 The realizations of the Accentual Phrase in French intonation. Probus 14 (special issue on Intonation in the Romance Languages): 147172.

Krifka, Manfred 2007 Basic notions of information structure. In: Caroline Féry and Manfred Krifka (eds.), Interdisciplinary Studies of Information Structure 6, Potsdam.

Ladd, Robert Dwight. 2006. Intonational Phonology. Cambridge University Press (first edition 2006).

Loevenbruck, Hélène 1999 Articulatory effects of contrastive emphasis on the Accentual Phrase in French. Journal of Acoustic Society of America, 106(4) : 1553-1573.

Lucci, Vincent 1983 Etude Phonétique du Français Comtemporain à travers la Variation Situationnelle. Grenoble: Publications de l'Université des Langues et des Lettres de Grenoble.

Mertens, Piet 1992 L'accentuation de syllabes contiguës. International Journal of Applied Linguistics, 95-96: 145-165.

Mertens, Piet 2004 Quelques allers-retours entre la prosodie et son traitement automatique. Le français moderne, 72(1): 39-57.

Michelas, Amandine and Mariapaola D'Imperio 2010a Durational cues and prosodic phrasing in French: Evidence for the intermediate phrase. Proceedings of International Conference on Speech Prosody 2010, 100881:1-4. Chicago, United-States.

Michelas, Amandine and Mariapaola D'Imperio, M 2010b Indices phonétiques et contraintes phonologiques: Caractérisation du syntagme intermédiaire en français. Actes des XXVIIIème Journées d'Etude sur la Parole, Mons, Belgique, 77-81.

Michelas, Amandine and Mariapaola D'Imperio 2010c Rôle des indices globaux dans la définition des constituants prosodiques en parole spontanée en français. Paper presented at the Journées Rhapsodie de juillet 2010. Toulouse. France

Pasdeloup, Valérie 1990 Modèle de règles rythmiques du français appliqué à la synthèse de parole. PhD Dissertation, Université de Provence, Aix-en-Provence, France.

Pierrehumbert, Janet 1994. Alignment and prosodic heads. In: Proceedings of the Eastern States Conference on Formal Linguistics 10: 268-286. 
Post, Brechtje 2000 Tonal and Phrasal Structures in French Intonation. The Hague: Holland Academic Graphics.

Rooth, Mats 1992 A theory of focus interpretation. Natural Language Semantics 1: 75116.

Rossi, Mario 1985 L'intonation et l'organisation de l'énoncé. Phonetica 42 :135-153.

Rossi, Mario 1999 L'intonation: Le Système du Français. Gap: Orpheus.

Selkirk, Elisabeth 2000 The interaction of Constraints on Prosodic Phrasing". In: Merle Horne, Prosody: Theory and Experiment (eds.), 231-262. Dordrecht: Kluwer Academic Publishing.

Shih, Chilin 1986 The Prosodic Domain of Tone Sandhi in Chinese. PhD dissertation. University of California San Diego, La Jolla, CA, USA.

Touati, Paul 1987 Structures Prosodiques du Suédois et du Français. Lund : Lund University Press.

Vaissière, Jacqueline 1974 On French prososdy. Research Laboratory of Electronics Progress Report 115: 212-223.

Vaissière, Jacqueline 1992 Rhythm, accentuation and final lengthening in French. In: Johan Sundberg, Lennard Nord and Rolf Carlson (eds.), Music, Language, Speech and Brain. Houndmills: MacMillan Press.

Welby, Pauline 2002 The realization of early and late rises in French intonation: A production study. Proceedings of the Speech Prosody Conference 2002, 695-698. Aix-enProvence, France.

Welby, Pauline 2006 French intonational structure: Evidence from tonal alignment. Journal of Phonetics 34(3): 343-371. 